\title{
O PAPEL DA PRODUÇÃO TEXTUAL NA EDUCAÇÃO DE JOVENS E ADULTOS: O LIVRO DIDÁTICO EM ANÁLISE
}

\author{
Rafaela Cristine Merli ${ }^{\mathrm{i}}$ \\ Andreia Cunha Malheiros Santana ${ }^{\mathrm{ii}}$
}

\begin{abstract}
Resumo: Este artigo tem como objetivo analisar duas propostas de produção textual presentes no livro didático Caminhar e Transformar (Ferreira, 2013), destinado às séries finais do Ensino Fundamental, na modalidade da Educação de Jovens e Adultos. Para tal análise, foi elaborada uma ficha baseada na concepção de ensino presente nos PCN (Parâmetros Curriculares Nacionais) e na BNCC (Base Nacional Comum Curricular) e na contribuição de autores que trabalham com o livro didático, com o ensino e com a linguagem, entre eles Marcuschi (2008) e Bakhtin (1981). Este artigo é um recorte de uma pesquisa de cunho qualitativo, predominantemente descritiva, com uma abordagem interpretativista. A partir da análise realizada, foi possível constatar que as propostas estão organizadas por gêneros e que a tecnologia e os gêneros digitais, tal como os gêneros orais, foram mal aproveitados.
\end{abstract}

Palavras-chave: Educação de Jovens e Adultos; Livro Didático; Produção Textual.

\section{THE ROLE OF TEXTUAL PRODUCTION IN YOUTH AND ADULT EDUCATION: THE TEACHING BOOK IN ANALYSIS}

\begin{abstract}
This article aims to analyze two proposals for textual production present in the book Caminhar e Transformar, aimed at the final grades of Elementary Education, in the modality of Youth and Adult Education. For this analysis, a form was created based on the teaching concept present in the official documents and on the contribution of authors who work with the textbook, teaching and language, among them Marcuschi and Bakhtin. This article is an excerpt from a qualitative research, predominantly descriptive, with an interpretive approach. From the analysis carried out, it was possible to verify that the proposals are organized by genres and that technology and digital genres, as well as oral genres, were poorly used.
\end{abstract}

Keywords: Textbook; Adults And Young Adults; Writing

\section{Introdução}

Este artigo tem como objetivo analisar duas propostas de produção textual presentes no livro didático Caminhar e Transformar (Ferreira, 2013), destinado às séries finais do Ensino Fundamental, na modalidade da Educação de Jovens e Adultos. Por isso, articularemos a fundamentação teórica no tripé: produção textual, livro didático (doravante LD) e Educação de Jovens e Adultos (EJA). A escolha por focar o ensino de Língua Portuguesa no eixo da produção textual ocorreu por acreditar que ela é de fundamental (c) (1) (2)

2021 Merli; Santana. Este é um artigo de acesso aberto distribuído sob os termos da Licença Creative Commons Atribuição Não Comercial-Compartilha Igual (CC BY-NC- 4.0), que permite uso, distribuição e reprodução para fins não comerciais, com a citação dos autores e da fonte original e sob a mesma licença. 


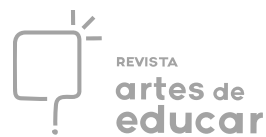

importância no processo de aquisição do conhecimento social e historicamente elaborado pelos homens. Matencio (2003) afirma que é função dos gêneros textuais a participação do aluno em atividades letradas das quais nunca havia participado antes. Partindo dessa afirmação, compreendemos que a variedade de gêneros em produção textual é necessária para o processo de ensino-aprendizagem, mas, mais do que isso, essa prática deve estar para além de utilizar textos que circulam na esfera pública, pois o uso de textos que promovam a reflexão sobre a condição social, política e ideológica é essencial para a aquisição do conhecimento socialmente elaborado, permitindo que o aluno conheça e elabore considerações a respeito de sua realidade.

A escolha do LD como instrumento mediador da aprendizagem encontrou respaldo nos estudos de Lajolo e Bunzen (2011). Para Lajolo (1996), o LD é um material que firmou como um recurso de prática pedagógica próprio da cultura escolar, transformando-se em um apoio didático. A autora ainda postula que o LD atua como um instrumento que estipula o conteúdo a ser ensinado, além de determinar as estratégias que serão utilizadas no ato pedagógico (LAJOLO, 1996), influenciando “o quê" e "como" ensinar.

Pode-se entender por estratégias as orientações tanto expressas no manual do professor, como aquelas presentes no exemplar do aluno, como por exemplo, "troque o texto com o colega", "faça a atividade numa folha separada", entre outras. Dessa forma, o LD se tornou um artefato cultural que orienta a prática docente na maioria das escolas brasileiras e que se modifica ao longo do tempo em função do momento histórico e dos sujeitos envolvidos.

Partindo do pressuposto que o LD influencia o trabalho do professor, este artigo analisou duas propostas de produção textual que integram o livro Caminhar e TransformarLingua Portuguesa (Ferreira, 2013), para os anos finais do Ensino Fundamental, na modalidade da Educação de Jovens e Adultos (EJA). O livro foi escrito por Priscila Ramos de Azevedo Ferreira, em 2013, e publicado pela editora FTD. Ele foi aprovado pelo Programa Nacional do Livro e do Material Didático (PNLD) de 2014, para vigência de 2014 a 2016, com prorrogação para 2017. No entanto, não houve, até 2019, uma nova edição do PNLD para EJA, estando em uso, portanto, os livros da seleção de 2014. A escolha deste título ocorreu por ele ter sido o livro mais adotado pelas escolas que oferecem a EJA na cidade de Londrina, Norte do Paraná.

A escolha por este tema de pesquisa ocorreu graças à trajetória profissional das autoras que já lecionaram para a EJA e identificaram que, em sua maioria, as propostas de produção de texto presentes nos livros didáticos não contemplam a realidade histórica vivenciada pelo Revista Interinstitucional Artes de Educar. Rio de Janeiro, V. 7, N. 1 - pág. 627-649 janeiroabril de 2021: "Pedagogias Vitais: Corpo, Desejo e Educação" DOI: 10.12957/riae.2021.54704 


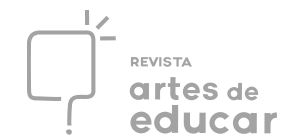

aluno desse nível de ensino, já que muitas são voltadas para o simples ato de praticar a escrita, dentro de um conjunto de regras que visa construir um texto repleto de frases que se agrupam de modo a ter sentido, mas não proporcionando, por meio da prática, a compreensão e a conscientização do sujeito enquanto ser no mundo que atua sobre a cultura e por ela é modificado. Em busca de respostas para esta inquietação, buscamos pesquisas no banco de teses da Capes e percebemos que há poucas pesquisas e publicações relacionadas ao estudo do livro didático da EJA, mais especificamente, sobre a produção de texto nos livros didáticos de Língua Portuguesa para EJA.

A metodologia empregada neste artigo privilegiou uma abordagem interpretativista, a qual, conforme Bortoni-Ricardo (2008), não pode desconsiderar o contexto sócio histórico, pois não é possível a observação do mundo sem considerar as práticas sociais e seus significados vigentes. A fim de analisar as produções textuais, foi elaborada uma ficha fundamentada na concepção de ensino presente na Base Nacional Comum Curricular (BNCC) articulada à fundamentação teórica que embasou este artigo - a saber: Bunzen (2011) e Lajolo (1996), no que se refere ao LD e a sua função como suporte escolar/mediador no processo de ensino e aprendizagem, e Bakhtin (1981) e Marcuschi (2008), no que se refere aos gêneros textuais ${ }^{\mathrm{iii}}$, entre outros.

Este artigo está dividido em três seções: primeiramente, apresentamos o LD enquanto um artefato cultural construído em relação com a sociedade. Em seguida, analisamos as duas propostas de produção textual escolhidas. Para finalizar, apresentamos as considerações finais deste estudo.

\section{O livro didático e as orientações oficiais}

Durante muito tempo, não houve um LD específico para os estudantes da EJA, pois, de acordo com Mello (2010), o material para essa etapa do ensino é escasso, levando os professores a utilizarem materiais voltados à educação "regular", os quais não levavam em consideração o conhecimento de mundo do estudante da EJA, já que não eram voltados para esse público. Sendo assim, esse material, quando utilizado com o público já evadido da escola, torna-se infantilizado, o que pode dificultar o processo de ensino-aprendizagem para esses estudantes.

A conquista da Educação de Jovens e Adultos (EJA) teve seu ápice na década de 1980, em um momento pós-ditadura, quando o governo reconheceu, a partir da Revista Interinstitucional Artes de Educar. Rio de Janeiro, V. 7, N. 1 - pág. 627-649 janeiroabril de 2021: "Pedagogias Vitais: Corpo, Desejo e Educação" DOI: 10.12957/riae.2021.54704 
democratização, o direito dos jovens e adultos de concluir o Ensino Fundamental e o Ensino Médio, quando não concluídos na idade regular. Nesse momento, como conquista para a sociedade brasileira, houve a consolidação da Constituição de 1988, a qual passou a contemplar novos direitos e estruturas do processo de democratização. Contudo, a respeito do público da EJA, Silva postula que:

Pode-se perceber, hoje, a heterogeneidade do aluno presente na sala de aula. São homens e mulheres, jovens e adultos, negros e brancos, empregados e desempregados ou pessoas em busca do primeiro emprego e pessoas deficientes, em sua maioria moradores de comunidades periféricas dos grandes centros urbanos e em busca da escolaridade como possibilidade para a melhoria da sua condição socioeconômica e cultural. (SILVA, 2009, p. 62)

Para que seja realizado um trabalho que propicie uma prática voltada para a formação humana e cidadã, proporcionando ao educando a capacidade de reflexão e tomada de consciência, é necessário conhecer o público da EJA e seu percurso histórico, para que o professor esteja preparado para atuar de forma que os estudantes possam se tornar sujeitos atuantes e conscientes socialmente.

Conforme dados do censo escolar de 2019, o número de matrículas nesta modalidade de ensino chegou a 2.625.462, nas redes estadual e municipal (Brasil, 2019). A partir dessas informações, podemos compreender a importância da EJA, havendo a necessidade de investigar como os conteúdos escolares são estruturados no LD, pois entendemos que esse material destinado à EJA deve ser desenvolvido exclusivamente para esse grupo de estudantes. Sendo assim, esse instrumento deve levar em consideração o educando e sua realidade e, ao mesmo tempo, garantindo o acesso e a compreensão do conhecimento científico/histórico do ser humano. Ademais, o LD, além de integrar o estudante ao mundo do trabalho, deve desenvolver a sua leitura crítica sobre a realidade em que vive, para então poder modificá-la, ou seja, o LD deve partir da realidade do estudante, mas não pode ficar preso a ela.

Partimos do pressuposto de que o LD é mais do que um simples material utilizado pelo professor. Trata-se de uma ferramenta que pretende atender aos currículos escolares, sendo, portanto, repleto de significados. Dessa forma, Bunzen (2011, p. 887) compreende a necessidade de entender que "as práticas escolares encontram-se historicamente marcadas por movimentos de permanência, rupturas, deslocamentos, sedimentação, tensão e escolhas curriculares. ” Assim, é possível afirmar que o LD sofreu alterações ao longo do tempo, como 


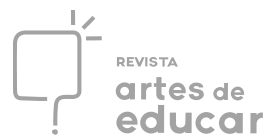

sua estrutura e as diversas temáticas que o compõem. Como exemplo, citamos a inclusão de questões referentes ao preconceito racial, étnico, sexual e de gênero nesse material.

No processo de ensino e aprendizagem, o LD tem grande importância. De acordo com Rojo e Batista (2003), em muitas situações o LD é o único referencial teórico a que o professor tem acesso. Mais do que isso, "o livro didático faz parte da cultura e da memória visual de muitas gerações e, ao longo de tantas transformações na sociedade, ele ainda possui uma função relevante para a criança, na missão de atuar como mediador na construção do conhecimento." (FREITAS; RODRIGUES, 2008, p. 01).

A elaboração do livro didático depende de muitos fatores. Um deles é a necessidade de adaptar o material aos documentos legais para que possa integrar a lista de livros aprovados pelo Programa Nacional do Livro e do Material Didático (PNLD), o qual, uma vez aprovado, pode ser adotado pelas escolas públicas, significando uma venda bastante lucrativa para as editoras.

Entre os documentos oficiais que regulam o ensino e, consequentemente, influenciam a elaboração dos materiais didáticos, citaremos dois: os Parâmetros Curriculares Nacionais (PCN) e a Base Nacional Comum Curricular (BNCC). Em relação aos PCN de Língua Portuguesa das séries finais do Ensino Fundamental, o documento aponta que sua finalidade é “contribuir para garantir a todos os alunos o acesso aos saberes linguísticos necessários para o exercício da cidadania." (BRASIL, 1998, p. 19).

Os PCN atuam como um parâmetro para nortear os processos pedagógicos, alegando que esses processos devem proporcionar ao estudante uma formação de competência discursiva e linguística, desenvolvendo sua capacidade de leitor e produtor de textos críticos. Ainda, é importante ressaltar que o documento já sinalizava a necessidade de adequação aos gêneros e de reescrita dos próprios textos.

Sendo assim, a produção de texto deve propiciar ao aluno realizar um processo de interlocução a partir das diferentes práticas sociais que fazem parte de seu cotidiano. É através da produção textual que o educando, além de relacionar as práticas de seu convívio social às características históricas das quais faz parte, poderá estabelecer referências culturais, organizando, produzindo, criticando e interferindo na sociedade que o cerca.

Nesse sentido, tanto os PCN, quanto a BNCC propõem que o estudante desenvolva um maior protagonismo quanto às práticas de linguagem dentro e fora da sala de aula, ampliando o contato dos estudantes com gêneros textuais relacionados a vários campos de atuação e a várias disciplinas, partindo das práticas de linguagem já vivenciadas para seu desenvolvimento e criação de novas práticas e vivências. 
Conforme o documento, "trata-se de promover uma formação que faça frente a fenômenos como o da pós-verdade, o efeito bolha e a proliferação de ódio.”, sendo que essa formação deve ocorrer através do trabalho com gêneros "que circulam nos campos das práticas artístico-literárias, de estudo e pesquisa, jornalístico/midiático, de atuação na vida pública e campo da vida pessoal, cidadãs, investigativas.” (BRASIL, 2017, p. 135).

Por atuação na vida pública, pode-se entender o domínio das diferentes práticas de linguagem e não apenas aquelas voltadas para o mundo do trabalho. Com relação a isso, o LD da EJA apresenta uma particularidade que o diferencia dos demais livros destinados à Educação Básica: o seu interlocutor é um sujeito com um percurso que deve ser considerado, cabendo à escola, e ao material didático adotado, ampliar as possibilidades para o aluno, e não apenas prepará-lo para o mercado de trabalho. Por isso, é fundamental que o LD seja estruturado de tal forma que proporcione a reflexão das práticas sociais através da aquisição e desenvolvimento dos conhecimentos historicamente elaborados.

A produção de texto ${ }^{\text {iv }}$ é de fundamental importância no processo de aquisição do conhecimento social e historicamente elaborado pelos homens. Para Kleiman (2007, p. 2), "na escola existem (ou deveriam existir) possibilidades de experimentação que estão ausentes de situações mais tensas e competitivas como as do local do trabalho." E continua: "acredito que é na escola, agência de letramento por excelência de nossa sociedade, que devem ser criados espaços para experimentar formas de participação nas práticas sociais letradas" (KLEIMAN, 2007, p. 4). Dessa forma, é importante que o LD destinado à EJA contemple gêneros presentes no cotidiano dos estudantes, mas também proporcione o contato com gêneros de outras esferas, a fim de ampliar os conhecimentos dos estudantes.

De acordo com Bakhtin (2003), toda a atividade humana está ligada à linguagem. Dessa forma, o autor postula que o uso da língua se dá por meio de enunciados, os mais diversos, os quais podem ser orais ou escritos, concretos e únicos, proferidos pelos integrantes desse ou daquele campo de atividade humana. Esses enunciados refletem as condições específicas e as finalidades de cada referido campo não só por seu conteúdo (temático) e pelo estilo da linguagem, mas também pela seleção dos recursos lexicais, fraseológicos e gramaticais da língua, mas, acima de tudo, por sua construção composicional. (BAKHTIN, 2003, p. 261).

Por meio dessa afirmação, Bakhtin trata de gênero do discurso (gênero textual) como um tipo de enunciado que obedece às regras estruturais, levando em consideração o momento da produção, qual a circunstância de uso, para quem e o que está se comunicando, além dos recursos linguísticos para tal contexto de uso. O autor afirma ainda que "cada enunciado Revista Interinstitucional Artes de Educar. Rio de Janeiro, V. 7, N. 1 - pág. 627-649 janeiroabril de 2021: "Pedagogias Vitais: Corpo, Desejo e Educação" DOI: 10.12957/riae.2021.54704 
particular é individual, mas cada campo de utilização a língua elabora seus tipos relativamente estáveis de enunciados, os quais denominamos de gêneros do discurso." (BAKHTIN, 2003, p. 262).

Entre o discurso e o texto está o gênero, que é aqui visto como prática social e prática textual-discursiva. Ele opera como a ponte entre o discurso como uma atividade mais universal e o texto enquanto a peça empírica particularizada e configurada numa determinada composição observável. Gêneros são modelos correspondentes a formas sociais reconhecíveis nas situações de comunicação em que ocorrem. Sua estabilidade é relativa ao momento histórico-social em que surge e circula. (MARCUSCHI, 2008, p. 84)

Assim, os papéis variados que os sujeitos desempenham em sociedade determinam quais competências de leitura e escrita devem ter. Isso quer dizer que as práticas de linguagem são dinâmicas, pois mudam de acordo com o sujeito e com a situação a partir de condições sócio-históricas.

A importância dos gêneros do discurso está no fato de terem uma enorme diversidade de possibilidades de uso, os quais implicam as mais variadas situações de comunicação do cotidiano. Koch e Elias (2014) afirmam que a competência de conhecimento dos gêneros textuais "propicia a escolha adequada do que produzir textualmente nas situações comunicativas (...)" e que "essa competência possibilita aos sujeitos não só diferenciar os diversos gêneros, isto é, saber se estão diante de um horóscopo, um bilhete, um diário (...), como também identificar as práticas sociais que os solicitam" (KOCH; ELIAS, 2014, p. 55).

As práticas de linguagem, então, efetuam-se por meio dos gêneros textuais, que compreendem representações orais e escritas na construção dessas práticas. Os gêneros textuais, portanto, estabelecem as diversas possibilidades de comunicação, determinando modelos de práticas de linguagem. Em outras palavras, os gêneros trazem regularidades às práticas de linguagem, sendo, portanto, referência no processo de ensino-aprendizagem da linguagem.

Na própria $\mathrm{BNCC}$, há a indicação da ampliação do uso de gêneros textuais que se relacionam com diversos campos de atuação social, proporcionando novas experiências para o aluno. Mais especificamente, de acordo com o documento, "aprofunda-se, nessa etapa, o tratamento dos gêneros que circulam na esfera pública, nos campos jornalístico-midiático e de atuação na vida pública." (BRASIL, 2017, p. 134).

A BNCC considera que o estudante está, cada vez mais, interagindo com diversos tipos de interlocutores, principalmente por meio do uso das redes sociais. Assim, o 
documento propõe que, além dos gêneros que circulam na esfera pública, que se leve em consideração práticas de linguagem contemporâneas, como o comentar, redistribuir, publicar posts etc. (BRASIL, 2017).

\section{A produção de texto destinada à EJA}

O LD Caminhar e Transformar (FERREIRA, 2013) é dividido em quatro unidades e cada unidade é dividida em quatro capítulos. É importante ressaltar que se trata de um livro único para os quatro anos finais do Ensino Fundamental, o que significa que cada unidade deve ser abordada em um semestre o que equivale a um ano de escolaridade. Cada unidade tem um tema específico, nela é trabalhado a leitura, a análise linguística e a produção textual.

Para fins de análise, neste artigo, selecionamos duas propostas: Biografia/Autobiografia (Unidade 1, Capítulo 3) e Artigo de Opinião (Unidade 4, Capítulo 4), doravante situação 1 e 2 . As unidades são estruturadas por temas amplos, cabe aos capítulos delimitarem os gêneros que serão trabalhados, os temas propostos refletem aspectos essenciais das relações humanas, sociais e profissionais da vida desse alunado, como a questão da identidade, do meio ambiente, do trabalho e dos direitos humanos, estando em consonância com os temas sugeridos pelos PCN. A divisão das unidades, capítulos, temas e tipos de atividades está assim estabelecida:

Quadro 01 - Organização do Livro Didático “Caminhar e Transformar” para EJA de LínguaPortuguesa

\begin{tabular}{|c|c|c|}
\hline $\begin{array}{l}\text { UNIDADE } \\
\text { (TEMA) }\end{array}$ & CAPÍTULO (TÍTULO) & $\begin{array}{l}\text { PROPOSTA DE PRODUÇÃO } \\
\text { DE TEXTO }\end{array}$ \\
\hline \multirow{4}{*}{$\begin{array}{c}\text { Unidade } 1 \\
\text { Iguais e diferentes } \\
\text { - Identidade e } \\
\text { Diversidade }\end{array}$} & $\begin{array}{l}\text { Capítulo } 1 \text { - Atenciosamente... } \\
\text { Um abraço... Saudações - um } \\
\text { estudo de cartas }\end{array}$ & $\begin{array}{l}\text { Mãos à obra (Produção de texto) - } \\
\text { Carta }\end{array}$ \\
\hline & $\begin{array}{l}\text { Capítulo } 2 \text { - Cordelista, o rei } \\
\text { do verso ritmado }\end{array}$ & $\begin{array}{l}\text { Mãos à obra (Produção de texto) - } \\
\text { Poema de Cordel }\end{array}$ \\
\hline & $\begin{array}{l}\text { Capítulo } 3-\text { Quem foi, quem } \\
\text { é, quem será }\end{array}$ & $\begin{array}{l}\text { Mãos à obra (Produção de texto) - } \\
\text { Autobiografia e Biografia }\end{array}$ \\
\hline & Capítulo 4 - Mito e identidade & $\begin{array}{l}\text { Mãos à obra (Produção de texto) - } \\
\text { Pesquisa/ Narrando um mito }\end{array}$ \\
\hline \multirow{3}{*}{$\begin{array}{l}\text { Unidade } 2 \\
\text { Aqui é o meu } \\
\text { lugar - Meio } \\
\text { Ambiente e }\end{array}$} & $\begin{array}{l}\text { Capítulo } 1 \text { - Crônica: entre o } \\
\text { jornalismo e a literatura }\end{array}$ & $\begin{array}{l}\text { Mãos à obra (Produção de texto) - } \\
\text { Crônica narrativa }\end{array}$ \\
\hline & $\begin{array}{l}\text { Capítulo } 2 \text { - Quem conta um } \\
\text { conto aumenta um ponto! }\end{array}$ & $\begin{array}{l}\text { Mãos à obra (Produção de texto) - } \\
\text { Conto }\end{array}$ \\
\hline & Capítulo 3 - Versos, rimas e & Mãos à obra (Produção de texto) - \\
\hline
\end{tabular}

Revista Interinstitucional Artes de Educar. Rio de Janeiro, V. 7, N. 1 - pág. 627-649 janeiroabril de 2021: "Pedagogias Vitais: Corpo, Desejo e Educação" DOI: 10.12957/riae.2021.54704 


\begin{tabular}{|c|c|c|}
\hline \multirow[t]{2}{*}{ Sustentabilidade } & estrofes & Sarau/ Poemas \\
\hline & $\begin{array}{l}\text { Capítulo } 4-\text { Propaganda } \mathrm{e} \\
\text { persuasão }\end{array}$ & $\begin{array}{l}\text { Mãos à obra (Produção de texto) - } \\
\text { Propaganda }\end{array}$ \\
\hline \multirow{4}{*}{$\begin{array}{c}\text { Unidade } 3 \\
\text { Trabalho e } \\
\text { transformação }-\mathbf{O} \\
\text { mundo do } \\
\text { trabalho }\end{array}$} & $\begin{array}{l}\text { Capítulo } 1-\mathrm{O} \text { trabalho em } \\
\text { foco }\end{array}$ & $\begin{array}{l}\text { Mãos à obra (Produção de texto) - } \\
\text { Charge e tirinha }\end{array}$ \\
\hline & $\begin{array}{l}\text { Capítulo } 2-\text { Diálogos entre } \\
\text { campo e cidade }\end{array}$ & $\begin{array}{l}\text { Mãos à obra (Produção de texto) - } \\
\text { Paródia }\end{array}$ \\
\hline & $\begin{array}{l}\text { Capítulo } 3-\mathrm{A} \text { escolha da } \\
\text { carreira }\end{array}$ & $\begin{array}{l}\text { Mãos à obra (Produção de texto) - } \\
\text { Currículo }\end{array}$ \\
\hline & \begin{tabular}{|l|l} 
Capítulo $4-$ Trabalho e \\
qualidade de vida
\end{tabular} & $\begin{array}{l}\text { Mãos à obra (Produção de texto) - } \\
\text { Debate }\end{array}$ \\
\hline \multirow{4}{*}{$\begin{array}{c}\text { Unidade } 4 \\
\text { Mundo cidadão - } \\
\text { Cidadania e } \\
\text { Direitos Humanos }\end{array}$} & Capítulo 1 - Vozes do Brasil & $\begin{array}{l}\text { Mãos à obra (Produção de texto) - } \\
\text { Seminário }\end{array}$ \\
\hline & $\begin{array}{l}\begin{array}{l}\text { Capítulo } 2-\text { Diálogo entre } \\
\text { tempos }\end{array} \\
\end{array}$ & $\begin{array}{l}\text { Mãos à obra (Produção de texto) - } \\
\text { Entrevista }\end{array}$ \\
\hline & $\begin{array}{l}\text { Capítulo } 3-\text { Registrando a } \\
\text { vida }\end{array}$ & $\begin{array}{l}\text { Mãos à obra (Produção de texto) - } \\
\text { Reportagem }\end{array}$ \\
\hline & \begin{tabular}{|l}
$\begin{array}{l}\text { Capítulo } \\
\text { mundo }\end{array}$ \\
- Leituras do \\
\end{tabular} & $\begin{array}{l}\text { Mãos à obra (Produção de texto) - } \\
\text { Artigo de opinião }\end{array}$ \\
\hline
\end{tabular}

Fonte: As autoras, a partir do livro analisado.

A partir do quadro acima, podemos observar que o LD apresenta, no total, dezesseis propostas de produção de texto, quatro em cada semestre. A estrutura de cada unidade do LD analisado segue os princípios organizadores propostos pelos PCN (1998): USO $\rightarrow$ REFLEXÃO $\rightarrow$ USO, ou seja, todos os capítulos, de todas as unidades, iniciam com um exemplo do gênero a ser estudado, sendo seguido de atividades de interpretação textual e identificação de elementos relativos ao gênero, como: características estruturais, finalidade e esfera de circulação. Em seguida, são propostas atividades de análise linguística, isto é, como a linguagem é trabalhada no gênero em questão, propondo exercícios que relacionem conteúdos gramaticais ao texto lido. E, para finalizar cada capítulo, há a proposta de produção textual, de acordo com o gênero estudado. Merece destaque o fato do livro ser consumível, mas não haver espaço para a resposta dos estudantes.

Para analisar as propostas de produção textual foi elaborada uma ficha com 16 itens de análise, divididos em 3 eixos: 1. gênero e o uso da linguagem; 2. o desenvolvimento do estudante enquanto sujeito e 3. interação em sala de aula. Dessa forma, investigamos se os gêneros em estudo contemplam os tópicos constantes no quadro:

Quadro 02 - Ficha de análise. 


\begin{tabular}{|c|l|c|c|}
\hline \multicolumn{1}{|c|}{ Gênero e usos da linguagem } & $\mathbf{1}$ & $\mathbf{2}$ \\
\hline 1 & O gênero é contextualizado & $\mathrm{X}$ & $\mathrm{X}$ \\
\hline 2 & $\begin{array}{l}\text { Propõe que o aluno produza o gênero correto para a situação } \\
\text { comunicativa }\end{array}$ & $\mathrm{X}$ & $\mathrm{X}$ \\
\hline 3 & Revela o objetivo da produção & $\mathrm{X}$ & $\mathrm{X}$ \\
\hline 4 & Apresenta informações sobre leitor presumido & $\mathrm{X}$ & $\mathrm{X}$ \\
\hline 5 & Informa o suporte no qual o texto circulará & $\mathrm{X}$ & $\mathrm{X}$ \\
\hline 6 & Propõe o uso da tecnologia & - & - \\
\hline 7 & $\begin{array}{l}\text { Possibilita a reflexão sobre linguagem (escolha da variedade } \\
\text { linguística correta) }\end{array}$ & - & - \\
\hline \multicolumn{3}{|c|}{ O desenvolvimento do estudante enquanto sujeito } \\
\hline 8 & Leva em consideração o conhecimento de mundo do estudante & $\mathrm{X}$ & $\mathrm{X}$ \\
\hline 9 & $\begin{array}{l}\text { Permite ao aluno pensar e repensar sua própria identidade como } \\
\text { sujeito }\end{array}$ & $\mathrm{X}$ & $\mathrm{X}$ \\
\hline 10 & Integra diferentes áreas do conhecimento & $\mathrm{X}$ & $\mathrm{X}$ \\
\hline 11 & Tem ênfase em questões emergentes socialmente & $\mathrm{X}$ & $\mathrm{X}$ \\
\hline 12 & Respeita a diversidade social e cultural & $\mathrm{X}$ & $\mathrm{X}$ \\
\hline 13 & Amplia o contato dos estudantes com gêneros diversificados? & - & - \\
\hline \multicolumn{2}{|c|}{ Interação em sala de aula } & $\mathrm{X}$ & $\mathrm{X}$ \\
\hline 14 & Possibilita a interação entre aluno/aluno & - & - \\
\hline 15 & $\begin{array}{l}\text { Permite ao professor fazer a mediação entre o aluno e a atividade } \\
\text { desenvolvida/conteúdo }\end{array}$ & - & $\mathrm{X}$ \\
\hline 16 & Propõe a reescrita e a autoavaliação do texto produzido \\
\hline
\end{tabular}

\section{Fonte: As autoras.}

Em relação ao primeiro tópico de análise, as duas propostas apresentam o gênero a ser estudado no início de cada capítulo, dando exemplos e apresentando o gênero numa situação real de comunicação. Essas informações serão importantes para a produção textual, através delas, o estudante poderá estabelecer o primeiro contato com o gênero e como será a produção de texto que irá produzir, observando sua estrutura e linguagem, percebendo o contexto no qual tal gênero se insere:

Quadro 03 - Contextualização do gênero

\begin{tabular}{|c|c|}
\hline Situação 1 & Situação 2 \\
\hline $\begin{array}{l}\text { Durante o capítulo, são apresentadas } \\
\text { algumas biografias de personalidade } \\
\text { conhecidas, como o Pelé. A contextualização } \\
\text { acontece por meio de exercícios, convidando } \\
\text { o aluno a pensar onde esse tipo de texto } \\
\text { poderia ser encontrado. }\end{array}$ & $\begin{array}{l}\text { Durante o capítulo, são expostos alguns } \\
\text { exemplos do artigo de opinião e sua } \\
\text { estrutura. No entanto, não há indicação de } \\
\text { circulação social do gênero, ou seja, onde } \\
\text { pode ser encontrado. }\end{array}$ \\
\hline Fonte: Ferreira, 2013, p. 50. & Fonte: Ferreira, 2013, p. 248-9. \\
\hline
\end{tabular}




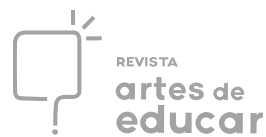

Contextualizar o gênero é importante para que o aluno estabeleça um sentido para aprendê-lo e perceba em que situações aquele texto deve ser formulado. "É necessário que o estudante compreenda, na prática, o uso real do gênero estudado, para que, a partir dessa interação, possa “construir realidades sociais, papéis e identidades, não apenas reproduzir o já dado." (KLEIMAN, 2012, p. 27).

Além da contextualização feita ao longo da unidade, a parte destinada a produção textual intitulada "Mãos à obra" apresenta uma explicação sobre o objetivo da produção e uma situação hipotética na qual o gênero trabalhado durante a unidade seja necessário.

Desta forma, o item "propõe que o aluno produza o gênero correto para a situação comunicativa" é atendido pelas duas propostas em análise, pois, conforme dito anteriormente, cada capítulo trata de um gênero específico, desde o seu modelo à sua produção. Ao propor o gênero ideal para determinada situação comunicativa, "o aluno se prepara para enfrentar as situações reais da vida diária, pois a seleção dos gêneros deve estar atenta para esse lado da vida diária" (MARCUSCHI, 2008, p. 217).

Quadro 04 - O gênero e a situação comunicativa

\begin{tabular}{|l|l|}
\hline \multicolumn{1}{|c|}{ Situação 1 } & \multicolumn{1}{|c|}{ Situação 2 } \\
\hline $\begin{array}{l}\text { Mãos à obra - Produção de Texto - } \\
\text { Autobiografia e biografia. }\end{array}$ & $\begin{array}{l}\text { Mãos à obra - Produção de Texto - Artigo } \\
\text { de opinião }\end{array}$ \\
$\begin{array}{l}\text { Você vai produzir uma autobiografia e a } \\
\text { biografia de um colega. Depois, a turma vai } \\
\text { fazer um livro com as produçóes para que } \\
\text { todos possam ler e conhecer várias histórias } \\
\text { de vida. }\end{array}$ & $\begin{array}{l}\text { Prepare-se para produzir um artigo de } \\
\text { opinião sobre os benefícios e prejuízos } \\
\text { trazidos pela internet, defendendo seu } \\
\text { ponto de vista a respeito do tema. }\end{array}$ \\
\hline \multicolumn{1}{|c|}{ Fonte: Ferreira, 2013, p. 50. } & \multicolumn{1}{|c|}{ Fonte: Ferreira, 2013, p. 248-9. } \\
\hline
\end{tabular}

As produções estão integradas ao estudo do gênero presente em cada capítulo. Depois da apresentação do tema da produção, são apresentados alguns tópicos com orientações para a escrita do texto. Na situação 1, aparecem os seguintes tópicos: "Escrevendo a autobiografia" e "Escrevendo a biografia de um colega". Na situação 2, há os seguintes tópicos: "Planejando", "Escrita do texto", "Revisão e reescrita" e "Apresentação oral". As diretrizes para os alunos são redigidas em formato de tópicos escritos no modo imperativo e as indicações sobre a linguagem utilizada aparecem nesses tópicos também. Este formato está presente em todas as unidades do livro. Tendo como base a reflexão de Marcuschi:

Mesmo que o texto escrito desenvolva um uso linguístico interativo não do tipo comunicação face a face, deve, contudo, preservar os papéis que cabem 
ao escritor e ao leitor para cumprir sua função, sob pena de não ser comunicativo. (2008, p. 53)

O estudante precisa compreender em qual contexto a produção de texto solicitada se encaixa, assim ele será capaz de articular as suas ideias e intenções de forma adequada a cada situação comunicativa. Nesse sentido, pode-se afirmar que os gêneros textuais, mais do que objetos de interação social, tornam-se materiais para a prática pedagógica com textos visando o aprendizado das funções sociais da língua

Da mesma forma, o tópico "Revela o objetivo da produção" também foi atendido pelas duas propostas.

Quadro 05 - Objetivo da Produção

\begin{tabular}{|c|l|}
\hline \multicolumn{1}{|c|}{ Situação 1 } & \multicolumn{1}{c|}{ Situação 2 } \\
\hline $\begin{array}{l}\text { Escrever a autobiografia/biografia para } \\
\text { integrar um livro. }\end{array}$ & $\begin{array}{l}\text { Fazer uma apresentação oral do artigo de } \\
\text { opinião para que seja feito um debate e o } \\
\text { aluno possa praticar a argumentação a partir } \\
\text { de diferentes pontos de vista. }\end{array}$ \\
\hline Fonte: Ferreira, 2013, p. 50. & \multicolumn{1}{c|}{ Fonte: Ferreira, 2013, p. 248-9. } \\
\hline
\end{tabular}

Para Geraldi (1993), existe a necessidade de uma finalidade para a produção textual e, mais que isso, é indispensável que o aluno compreenda a razão pela qual ele deve produzir determinado texto. Complementando Geraldi, Marcuschi (2008, p. 79) afirma que "quando um falante ou escritor se põe a usar a língua (produzir textos), ele pode fazer escolhas diversas a partir do sistema virtual da língua, mas tem que se decidir por uma escolha", pois existem diversas possibilidades para a produção textual e será necessário escolher uma, esta escolha ocorre a partir do objetivo da produção.

Assim, os objetivos da produção textual devem estar claros para que o estudante, ainda aprendiz em relação à produção de texto, entenda o que deve ser feito e como deve ser feito, para que possa planejar a sua escrita, realizando escolhas conscientes, como quais palavras usar, quais ideias escrever e a melhor forma de organizá-las.

Outra questão importante na produção textual é apresentar o leitor presumido para a produção. Corroborando com esta afirmação, Marcuschi (2008, p. 78) declara que "um dos problemas constatados nas redações escolares é precisamente este: não se define com precisão a quem o aluno se dirige." Isso quer dizer que definir o interlocutor (ou leitor presumido) é essencial para a produção textual, pois, caso contrário, o aluno irá pressupor que 
o seu único leitor será o professor, fazendo com que os objetivos reais da produção de texto não sejam alcançados. As duas produções selecionadas apresentam um leitor presumido:

Quadro 06 - Leitor presumido

\begin{tabular}{|c|c|}
\hline Situação 1 & Situação 2 \\
\hline Colegas de classe/Estudantes da escola & Colegas de classe \\
\hline Fonte: Ferreira, 2013, p. 50. & Fonte: Ferreira, 2013, p. 248-9. \\
\hline
\end{tabular}

Vale destacar que, apesar de todas as propostas apresentarem o interlocutor a quem se destina o texto no momento da produção, no comando da atividade não consta quem seriam os leitores presumidos em situações reais de uso do gênero, mas ao longo do capítulo, essa informação foi identificada. Contudo, seria melhor que ela fosse reiterada na seção "Mãos à obra", pois informar o interlocutor "aponta o tipo de linguagem empregada no texto, a maneira de expor o assunto, em virtude do gênero escolhido e do lugar de circulação, conduzindo o autor a uma construção mais adequada do texto." (MENEGASSI, 2003, p. 57).

$\mathrm{O}$ fato de algumas informações importantes para a produção textual estarem diluídas ao longo da unidade e não serem retomadas no momento da produção textual, pode criar alguma confusão para o estudante, que pode ter esquecido o que já foi trabalhado ou mesmo o professor pode ter excluído algum tópico da unidade em que havia uma informação importante para o estudante. Por isso, julgamos importante que esta informação seja retomada de forma mais clara e objetiva na seção destinada à produção textual.

O próximo tópico analisado se refere à presença de informações sobre o suporte no qual o texto circulará. Tais informações são encontradas nas duas propostas em análise, ou seja, as duas informam, com clareza, onde o texto produzido pelo aluno circulará. Para produzir um texto adequado é necessário que o aluno (re)conheça o suporte no qual determinado gênero é veiculado. Conforme os PCN (1998), conhecer o suporte de veiculação do gênero estudado desenvolve a capacidade do aluno em construir as expectativas em relação à sua produção, como pressupor antecipadamente os sentidos que deseja estabelecer para seu texto.

Quadro 07 - Suporte de veiculação do texto produzido.

\begin{tabular}{|c|l|}
\hline \multicolumn{1}{|c|}{ Situação 1 } & \multicolumn{1}{c|}{ Situação 2 } \\
\hline $\begin{array}{l}\text { Livro elaborado pelo professor com os } \\
\text { textos produzidos pelos alunos. }\end{array}$ & $\begin{array}{l}\text { Exposição do texto oralmente aos colegas de } \\
\text { classe. }\end{array}$ \\
\hline Fonte: Ferreira, 2013, p. 50. & \multicolumn{1}{|c|}{ Fonte: Ferreira, 2013, p. 248-9. } \\
\hline
\end{tabular}


Marcuschi (2008) afirma que o suporte foi desprezado durante um bom tempo no trabalho com os gêneros, pois o foco era o texto em si. Para ele, o suporte de um gênero é "um lócus físico ou virtual com formato específico que serve de base ou ambiente de fixação do gênero materializado como texto" (p. 174). Pode-se dizer que suporte de um gênero é uma superfície física em formato específico no qual o texto será veiculado, conhecer este suporte é fundamental para que o estudante faça as suas escolhas linguísticas. A única referência ao gênero oral aparece neste item, embora os documentos oficiais ressaltem a sua importância, ele ainda é pouco explorado nas propostas de produção textual.

O próximo tópico faz menção ao uso da tecnologia. Os PCN, mesmo em 1998, já orientavam sobre os gêneros e o uso da tecnologia, mas a BNCC retoma esta mesma ideia e incentiva o uso da tecnologia e dos gêneros: "Compreender, utilizar e criar tecnologias digitais de informação e comunicação de forma crítica, significativa, reflexiva e ética nas diversas práticas sociais (incluindo as escolares) para se comunicar" (BRASIL, 2017, p. 10). Nas duas propostas analisadas, percebemos que a tecnologia não foi bem aproveitada.

Quadro 08 - Possibilidades de uso da tecnologia.

\begin{tabular}{|c|l|}
\hline \multicolumn{1}{|c|}{ Situação 1 } & \multicolumn{1}{c|}{ Situação 2 } \\
\hline $\begin{array}{l}\text { Não faz menção ao uso de qualquer tipo de } \\
\text { tecnologia para a produção textual }\end{array}$ & $\begin{array}{l}\text { O único momento, no tópico da produção } \\
\text { textual, em que é citado algo relacionado à } \\
\text { tecnologia é a orientação para o estudante } \\
\text { fazer pesquisas na internet sobre o assunto. }\end{array}$ \\
\hline Fonte: Ferreira, 2013, p. 50. & \multicolumn{1}{c|}{ Fonte: Ferreira, 2013, p. 248-9. } \\
\hline
\end{tabular}

Embora haja uma sugestão de pesquisa na internet, em relação à orientação para o artigo de opinião, essa indicação, isoladamente, representa um subaproveitamento dos recursos tecnológicos.

$\mathrm{Na}$ atualidade, os gêneros relacionados à tecnologia são muitos e os estudantes têm acesso a eles quase o tempo todo. Sendo assim, possibilitar o uso da tecnologia nas práticas de produção textual é essencial, as duas propostas não levam em consideração a possibilidade de usar aplicativos ou outros recursos tecnológicos. Entretanto, devemos levar em consideração o perfil dos alunos da EJA. Muitos não têm acesso fácil aos meios tecnológicos. Outros, quando têm acesso, têm dificuldades no manuseio. Tais características são dificultadores do uso da tecnologia, mas tornam mais importante ainda a presença destes recursos na sala de aula, mais do que utilizar estes recursos, é necessário também incluir os gêneros oriundos do universo tecnológico. 
Para Marcuschi (2008), os gêneros virtuais exercem fascínio sobre as pessoas porque reúnem, num só meio, várias formas de expressão, tais como texto, som e imagem. Devemos considerar que o trabalho textual deve ser a partir dos gêneros considerados necessários à participação social, aprofundando o que o aluno já tem de conhecimento para que esteja preparado para as diversas situações comunicativas. De acordo com Kensky,

as mídias, como tecnologias de comunicação e de informação, invadem o cotidiano das pessoas e passam a fazer parte dele. Para seus frequentes usuários, não são mais vistas como tecnologias, mas como complementos, como companhias, como continuação de seu espaço de vida. (2003, p. 25)

A tecnologia deve fazer parte das propostas de produção de texto. Nas duas propostas analisadas, faltou um aprofundamento nesse item, para que os estudantes pudessem ser inseridos nesse tipo de contexto de uso dos gêneros.

O próximo tópico aborda a temática das escolhas linguísticas realizadas pelos estudantes. As duas propostas viabilizam o uso da variante linguística pertinente ao contexto de uso do gênero, como mostra o exemplo:

Quadro 09 - Linguagem utilizada

\begin{tabular}{|c|c|}
\hline Situação 1 & Situação 2 \\
\hline $\begin{array}{l}\text { Embora não exija a adoção da norma } \\
\text { padrão da língua, pede que o estudante } \\
\text { utilize a } 3^{\circ} \text {. Pessoa do singular }\end{array}$ & $\begin{array}{l}\text { Neste caso, não há uma indicação precisa } \\
\text { sobre o uso da norma padrão da língua. } \\
\text { Contudo, há as seguintes orientações: "A } \\
\text { linguagem deve ser objetiva (...)" e "A } \\
\text { linguagem está adequada à situação de } \\
\text { comunicação?". }\end{array}$ \\
\hline Fonte: Ferreira, 2013, p. 50. & Fonte: Ferreira, 2013, p. 248-9. \\
\hline
\end{tabular}

As duas propostas de produção textual valorizam a utilização da norma padrão da língua, o que não está errado, desde que o contexto assim o exija, mas o estudante precisa ser levado a perceber que a língua tem diferentes graus de formalidade e que devemos escolher a variante correta de acordo com o contexto. No entanto, entendemos que o fato de privilegiar unicamente a variante de prestígio social não oportuniza a integração do sujeito à sociedade. É necessário que a escola trabalhe com a norma padrão, sem que isso signifique inferiorizar o estudante que domina a variante popular da língua.

Nesse sentido, Antunes faz uma excelente reflexão a respeito do uso da variante adequada ao contexto de uso do gênero: “apenas pela convivência com textos escritos formais, pela leitura e pela análise das especificidades desses textos é que alguém pode 


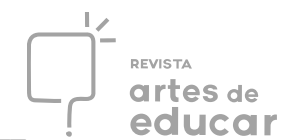

apreender os modos de formulação próprios da escrita." (ANTUNES, 2008, p. 199). Pensando no perfil da EJA, consideramos que o estudante deve ser orientado em relação aos diversos graus de formalidade e variantes necessárias a cada contexto de uso do gênero.

Marcuschi (2008) complementa o que diz Antunes e afirma que o ensino da Língua Portuguesa não se dá pela gramática em si, mas numa perspectiva que deve ser trabalhada por meio de textos. De acordo com o autor, o trabalho com textos não tem um limite esclarecido, visto que um texto pode ser tanto oral quanto escrito, mas postula alguns aspectos que podem ser trabalhados, como: o desenvolvimento histórico da língua, as diversidades de variação linguística, as relações entre fala e escrita, funcionamento e definição de categorias gramaticais, entre outros.

Relativamente aos tópicos de investigação presentes no eixo 2, as duas propostas em análise atendem aos pontos destacados na tabela. O próprio gênero escolhido para a produção de texto permite a utilização do conhecimento de mundo dos estudantes para o seu desenvolvimento, o aluno precisará fazer uso de suas experiências pessoais e/ou profissionais para produzir tanto a sua autobiografia, como o seu currículo.

Mais do que isso, para Bakhtin o sujeito se constrói na relação social com o outro e deixa a sua marca no que escreve:

Todo enunciado tem uma espécie de autor, que no próprio enunciado escutamos como seu criador. Podemos não saber absolutamente nada sobre o autor real, como ele existe fora do enunciado. As formas dessa autoria real podem ser muito diversas. Uma obra qualquer pode ser produto de um trabalho de equipe, pode ser interpretado como trabalho hereditário de várias gerações, e apesar de tudo, sentimos nela uma vontade criativa única, uma posição determinada diante da qual se pode reagir dialogicamente. A reação dialógica personifica toda enunciação à qual ela reage. (Bakhtin, 1981, p. 159)

O estudante, ao produzir um enunciado, faz escolhas linguísticas que marcam a sua subjetividade e sua relação com o mundo que o cerca. A fim de que a educação seja significativa para este estudante, ela deve proporcionar a reflexão sobre o mundo, sobre as questões sociais e sobre a própria linguagem.

Outro autor importante que trabalha com a noção de sujeito é Marcuschi (2008). Para ele, precisamos reconhecer a noção de sujeito como um ser essencialmente histórico, portanto, um sujeito ideológico. Ao fazer as suas escolhas linguísticas e temáticas, o autor reposiciona o sujeito histórico. Nesse sentido, vale retomar o que Marcuschi diz: 
Em suma, pode-se dizer que o sujeito não é assujeitado nem totalmente individual e consciente, mas produto de uma clivagem da relação entre linguagem e história. Em não sendo totalmente livre, nem determinado por alguma exterioridade, o sujeito se constitui na relação com o outro (...), o sujeito não é a única fonte do sentido, pois ele se inscreve na história e na língua. (2008, p. 70)

Assim, podemos entender que o sujeito é constituído histórica, cultural e ideologicamente, e ainda, que pode e deve se reconhecer como sujeito de sua própria história, consciente de si e de sua realidade, criando e recriando sua identidade, compreendendo que faz parte da história, que o seu lugar na sociedade é determinante no/do seu modo de dizer. Neste sentido, as duas propostas analisadas propõem uma retomada deste sujeito: o aluno deverá escrever sobre si, levando em conta as suas experiências pessoais. De acordo com Marcuschi:

a consciência de si mesmo só é possível se experimentada por contraste. Eu não emprego eu a não ser dirigindo-me a alguém, que será na minha alocução um tu. Essa condição de diálogo é que é constitutiva da pessoa, pois implica em reciprocidade - que eu me torne tu na alocução daquele que por sua vez se designa por eu. (MARCUSCHI, 2008, p. 71)

Respeitar a subjetividade do aluno é um fator positivo nas duas propostas apresentadas, pois leva em consideração que o estudante da EJA é alguém com outros saberes e que estes saberes integram a sua subjetividade. Ao produzir um texto, o estudante deve(ria) se colocar como sujeito de seu próprio discurso, permitindo que exponha suas ideias, seu posicionamento a respeito dos acontecimentos no mundo, o que o leva a reconhecer seu papel enquanto cidadão atuante na sociedade.

Quadro 10 - Permite ao aluno pensar e repensar sua própria identidade como sujeito

\begin{tabular}{|l|l|}
\hline \multicolumn{1}{|c|}{ Situação 1 } & \multicolumn{1}{|c|}{ Situação 2 } \\
\hline $\begin{array}{l}\text { Organize os fatos mais marcantes de sua vida. } \\
\text { (...) desde a primeira lembrança significativa até } \\
\text { o acontecimento mais recente. }\end{array}$ & $\begin{array}{l}\text { Para ajudá-lo na construção dos } \\
\text { argumentos e dos parágrafos de } \\
\text { desenvolvimento, propomos algumas } \\
\text { questões para reflexão. (...) } \\
\text { - Que cuidados devemos ter quando } \\
\text { acessamos sites e informamos dados } \\
\text { pessoais na internet? } \\
- \text { Em sua opinião, todas as pessoas } \\
\text { devem ter acesso às ferramentas } \\
\text { oferecidas pela informática? O que } \\
\text { deve ser feito para que um número } \\
\text { maior de brasileiros possa utilizar }\end{array}$ \\
\hline
\end{tabular}

Revista Interinstitucional Artes de Educar. Rio de Janeiro, V. 7, N. 1 - pág. 627-649 janeiroabril de 2021: "Pedagogias Vitais: Corpo, Desejo e Educação" DOI: 10.12957/riae.2021.54704 
$(\ldots)$

- Em sua opinião, é possível viver atualmente sem, de algum modo, utilizar computadores? Fonte: Ferreira, 2013, p. 248-9.

Sendo assim, o sujeito deve compreender seu lugar no discurso, sabendo que pode ocupar diferentes posições discursivas, o que pode ser percebido nas duas propostas investigadas. Ao criar uma autobiografia, ou um artigo de opinião, o aluno se coloca como sujeito de sua história e simultaneamente utiliza o seu conhecimento de mundo para selecionar o que deve ou não integrar suas produções textuais. As duas propostas analisadas permitem que o aluno repense sua trajetória de vida, sua identidade, o que o levou ao lugar onde está, suas próprias opiniões, enfim, ambas as propostas enfatizam a posição do estudante como sujeito do seu próprio discurso.

Isto posto, as produções propostas, em todo o seu processo, trazem a possibilidade de o aluno compreender como sua participação social é importante, mesmo que apenas produzindo um texto para ser exposto na escola, pois durante o desenvolvimento do seu texto é capaz de se posicionar criticamente frente à sua própria experiência de vida e diante das diferentes situações sociais.

Nesse sentido, observamos que as duas propostas em análise tratam de temas ou questões sociais emergentes e que permeiam o contexto dos estudantes.

Quadro 11 - Questões sociais

\begin{tabular}{|c|c|}
\hline Situação 1 & Situação 2 \\
\hline Cultura; história de vida. & Benefícios e malefícios da internet. \\
\hline Fonte: Ferreira, 2013, p. 50. & Fonte: Ferreira, 2013, p. 248-9. \\
\hline
\end{tabular}

A abordagem das diversas questões sociais emergentes proporciona ao estudante integrar várias áreas do conhecimento, sendo esse um tópico de análise que contempla as duas produções textuais em estudo.

Como temos visto até o momento, para que o estudante seja o autor do seu próprio discurso e cidadão atuante socialmente, é necessário que haja o trabalho com uma diversidade de conhecimentos. O que podemos observar é que o controle curricular fragmenta o ensino, ou seja, faz com que a formação humana e profissional dos estudantes seja também fragmentada e não tão crítica. 
O livro não propõe a integração das diferentes áreas do saber que integram o currículo dos estudantes, mas o professor pode complementar a discussão proposta no material e adaptar as propostas à realidade social do estudante.

No terceiro eixo apresentado, enfatizamos a necessidade da interação entre os alunos e entre os estudantes e o professor. As duas propostas em análise propõem a interação aluno/aluno:

Quadro 12 - Interação aluno/aluno- Interação aluno/professor

\begin{tabular}{|c|c|}
\hline Situação 1 & Situação 2 \\
\hline $\begin{array}{l}\text { "Você vai produzir a biografia (..) de um } \\
\text { colega. Depois, a turma vai fazer (...) } \\
\text { "com um colega, vocês vão escrever a biografia } \\
\text { um do outro." }\end{array}$ & $\begin{array}{l}\text { "Reúna-se com alguns colegas em um } \\
\text { pequeno grupo e exponha seu ponto de } \\
\text { vista." }\end{array}$ \\
\hline $\begin{array}{l}\text { "Mostre ao professor para que faça comentários } \\
\text { e sugestões" } \\
\text { "(...) ajude o professor com a montagem do } \\
\text { livro". }\end{array}$ & $\begin{array}{l}\text { Não há orientação para interação entre } \\
\text { aluno-professor. }\end{array}$ \\
\hline Fonte: Ferreira, 2013, p. 50. & Fonte: Ferreira, 2013, p. 248-9. \\
\hline
\end{tabular}

Além da interação com os estudantes, somente a situação 1 propõe a interação entre o aluno e o professor, a fim de que esse faça a mediação do conhecimento. A figura do professor aparece na proposta da situação 1 como um parceiro e não como alguém cuja finalidade é corrigir o texto do estudante. Neste ponto, é importante destacar que o texto construído será "corrigido" pelos próprios alunos. Considerando que existe uma falta de habilidade por parte do aluno em produzir determinados gêneros, é função do professor ajudálo a obter a competência nessa prática.

Assim, o professor é um mediador essencial durante esse processo, pois cabe a ele, como maior conhecedor, naquele momento, proporcionar situações que levem o estudante a compreender a função social do que está aprendendo. Isso começa pela interação entre professor e aluno. Paulo Freire (1996, p. 47, grifos do autor), em citação já conhecida popularmente, frisou que "ensinar não é apenas transferir conhecimento, mas criar condições para a sua própria produção ou a sua construção.” Desse modo, mesmo antes do professor iniciar a mediação, é importante que interaja com os educandos, que se sinta seguro em permitir que lhe façam perguntas, pois o papel do professor não pode ser ignorado.

Para finalizar as duas propostas, há uma última orientação sobre a revisão do texto e a sua finalização, conforme quadro abaixo: 
Quadro 14 - Finalização

\begin{tabular}{|c|c|}
\hline Situação 1 & Situação 2 \\
\hline Finalização & Revisão e reescrita \\
\hline $\begin{array}{l}\text { Com todos os textos já elaborados e revisados } \\
\text { pelo grupo, ajude o professor com a } \\
\text { montagem do livro }\end{array}$ & $\begin{array}{l}\text { Após a produção dos textos, verifique se os } \\
\text { objetivos principais foram alcançados. } \\
\text { - A tese defendida está claramente } \\
\text { apresentada, de maneira coerente? } \\
\text { - Os eventuais exemplos e citações } \\
\text { reforçam a argumentação? } \\
\text { - A linguagem está adequada à situação de } \\
\text { comunicação? }\end{array}$ \\
\hline Fonte: Ferreira, 2013, p. 50. & Fonte: Ferreira, 2013, p. 248-9. \\
\hline
\end{tabular}

Embora não haja uma referência explícita à reescrita do texto, é possível inferir que tanto a biografia que integrará o livro, como o artigo de opinião deverão ser reescritos após a revisão textual, para que estejam isentos de erros ortográficos e gramaticais. Esta leitura coletiva é bastante positiva para que o estudante repense as escolhas feitas durante a elaboração do texto.

\section{Conclusão}

Por meio do estudo realizado, é possível afirmar que as duas propostas analisadas permitem aos estudantes se colocarem como sujeitos do seu próprio discurso, refletindo criticamente acerca dos temas abordados, repensando sua identidade e história de vida, condição fundamental para o exercício pleno da cidadania. Além disso, as produções textuais são trabalhadas em conjunto com o restante da unidade didática, o que permite uma compreensão mais profunda da estrutura do gênero a ser produzido, seu meio de circulação e seus objetivos. Também identificamos que as propostas possibilitam a interação entre os sujeitos (principalmente a interação aluno-aluno), o que lhes permite conhecer diferentes opiniões e vivências.

No entanto, mesmo o LD atendendo à maior parte dos itens analisados, algumas ausências merecem destaque: as produções não envolveram o uso da tecnologia, perdendo a oportunidade de favorecer o letramento digital destes estudantes. Entendemos que, de fato, o uso da tecnologia com a EJA nem sempre é possível, pois as próprias escolas, muitas vezes, não oferecem essa possibilidade e nem todos os alunos têm acesso a isso. No entanto, justamente por esses motivos, é interessante que, mesmo de forma simplificada, seja 


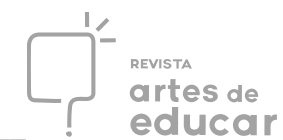

propiciado ao estudante algum tipo de aproximação da tecnologia, já que essa está presente no cotidiano. Mesmo a situação 2 sugerindo pesquisa na internet, não existe um aprofundamento ou qualquer outra orientação para o aluno sobre como e onde ele deve realizar essa pesquisa.

Outro problema encontrado, ao analisar isoladamente o tema da produção textual, foi a falta de reflexão sobre os níveis de formalidade da linguagem e a variação linguística existente no país. Ambas as propostas valorizaram exclusivamente a norma padrão, o que não é errado, mas a variação linguística em relação ao gênero poderia ter sido melhor trabalhada para que o estudante pudesse perceber que há diferentes níveis de formalidade na linguagem e que as duas situações apresentadas demandam a adoção da norma padrão.

Também destacamos que a produção de texto oral foi pouco aproveitada nas duas situações apresentadas. Além disso, as duas produções textuais analisadas apresentam um caráter bastante pragmático e, embora reconheçamos a relevância de as propostas terem uma base no contexto dos alunos, chamamos a atenção para o fato de que cabe à escola apresentar, da mesma forma, diferentes possibilidades e favorecer a compreensão dos gêneros secundários, mesmo que eles não façam parte do contexto social do estudante. Entendemos que a educação deve superar a lógica do capital, proporcionando uma formação que ultrapasse o imediatismo da nossa sociedade e forneça os conhecimentos socialmente elaborados e historicamente acumulados não só para que o estudante se "encaixe" no mercado de trabalho, mas também para que ele o questione, exercendo , assim, a sua cidadania . Para isso, é essencial que o aluno seja sujeito de sua história, pense e repense o seu contexto social para que possa intervir nele.

\section{REFERÊNCIAS}

ANTUNES, I. Língua, texto e ensino: outra escola possível. São Paulo: Parábola, 2009.

BAKHTIN, M. Problemas da Poética de Dostoievskí. Rio de Janeiro: Forense Universitária, 1981. Tradução: Paulo Bezerra.

BORTONI-RICARDO, S. M. O professor pesquisador: introdução à pesquisa qualitativa. São Paulo: Parábola, 2008.

BRASIL. Instituto Nacional de Estudos e Pesquisas Educacionais (Inep). Censo Escolar de 2019. Disponível em: http://portal.inep.gov.br/web/guest/resultados-e-resumos. Acesso em: 22 abr. 2020.

Ministério da Educação. Base Nacional Comum Curricular. 2017. Disponível em: http://basenacionalcomum.mec.gov.br/wp-

Revista Interinstitucional Artes de Educar. Rio de Janeiro, V. 7, N. 1 - pág. 627-649 janeiroabril de 2021: "Pedagogias Vitais: Corpo, Desejo e Educação" DOI: 10.12957/riae.2021.54704 
content/uploads/2018/06/BNCC_EI_EF_110518_versaofinal_site.pdf. Acesso em: 26 mai. 2020.

Ministério da Educação. Parâmetros Curriculares Nacionais: terceiro e quarto ciclos do ensino fundamental: língua portuguesa. Brasília: MEC, 1998.

BUNZEN, C. A fabricação da disciplina escolar Português. Revista Diálogo Educacional, v. 11, $\mathrm{n}^{\mathrm{o}} \quad 34, \quad$ p. 885-911, 2011. Disponível em: https://periodicos.pucpr.br/index.php/dialogoeducacional/article/view/4513. Acesso em 05 mai. 2020.

FERREIRA, P. R. de A. Caminhar e transformar - língua portuguesa: anos finais do ensino fundamental: Educação de Jovens e Adultos. São Paulo: FTD, 2013.

FREIRE, P. Pedagogia da autonomia: saberes necessários à prática educativa. São Paulo: Paz e Terra, 1996

FREITAS, N. K. RODRIGUES, M. H. O livro didático ao longo do tempo: a forma do conteúdo. Revista Da Pesquisa. Ano 5, V. 3, N. 1. Ago. 2007-Jul. 2008. Disponível em: www.ceart.udesc.br/revista_dapesquisa/volume3/numero1/plasticas/mellisa-neli.pdf Acesso em: 17 jun. 2020.

KENSKI, V. M. Tecnologias e ensino presencial e a distância. Campinas: Papirus,2003

KLEIMAN, A. B. Letramento e suas implicações para o ensino de língua materna. Revista Signo, v. 32, n. 53, p. 1-25, 2007

. A. B. EJA e o ensino da língua materna: relevância dos projetos de letramento. EJA em debate, v. 1, n. 1, nov. 2012. Disponível em: https://incubadora.periodicos.ifsc.edu.br/index.php/EJA/article/viewFile/322/pdf. Acesso em: 10 mai. 2020.

LAJOLO, M. Livro didático: um (quase) manual do usuário. Em Aberto, Brasília, ano 16, n.69, jan./mar. $1996 . \quad$ Disponível em: http://rbep.inep.gov.br/ojs3/index.php/emaberto/article/view/2368. Acesso em 08 jun. 2020.

MARCUSCHI, L. A. Produção textual, análise de gêneros e compreensão. São Paulo: Parábola Editorial, 2008.

MATENCIO, Maria de Lourdes Meirelles. Referenciação e retextualização de textos acadêmicos: um estudo do resumo e da resenha. Anais do III Congresso Internacional da ABRALIN. Rio de Janeiro: UFRJ, 2003.

MENEGASSI, R. J. Professor e escrita: a construção de comandos de produção de textos. Trabalhos em Linguística Aplicada, v. 42, jul/dez 2003. Disponível em: https://periodicos.sbu.unicamp.br/ojs/index.php/tla/article/view/8639372. Acesso em: 10 dez. 2019.

ROJO, R; BATISTA, A A G. (Org.). Livro didático de língua portuguesa, letramento e cultura da escrita. Campinas: Mercado de Letras, 2003. 
SANTOS, J. S. dos. Letramento, variação linguística e ensino de português. Linguagem em (Dis)curso, v. 5, n. 1, p. 119-134, jul/dez 2014. Disponível em: http://www.portaldeperiodicos.unisul.br/index.php/Linguagem_Discurso/article/view/3

04/320. Acesso em: 10 dez. 2019.

SILVA, N. N. da. Educação de jovens e adultos: alguns desafios em torno do direito à educação. Paidéia. Belo Horizonte, v. 6, n. 7, p. 61-72, 2009. Disponível em: http://www.fumec.br/revistas/paideia/article/view/951. Acesso em 05 dez. 2019.

SILVA, M. A. A fetichização do livro didático no Brasil. Educação e Realidade. Porto Alegre, v. 37, n. 3, p. 803-821, set/dez. 2012.

\footnotetext{
${ }^{\text {i }}$ Mestre em Educação pela UEL (Universidade de Londrina). Londrina/Paraná - Brasil. ORCID iD: https://orcid.org/0000-0001-7813-3338

ii Professora no Departamento de Letras Vernáculas e Clássicas. Coordenadora do Profletras. Professora no PPGEL. Londrina/Paraná - Brasil. ORCID iD https://orcid.org/0000-0002-3506-9716

iii Neste artigo, tal como defende Marcuschi, não será feita uma distinção entre gênero textual e gênero do discurso: "Não vamos discutir aqui se é mais pertinente a expressão 'gênero textual' ou a expressão 'gênero discursivo' ou 'gênero do discurso'. Vamos adotar a posição de que todas essas expressões podem ser usadas intercambialmente, salvo naqueles momentos em que se pretende, de modo explícito e claro, identificar algum fenômeno específico." (Marcuschi, 2008, p. 154)

iv Neste artigo, a concepção de texto advém dos estudos de Marcuschi, para quem "o texto é uma (re)construção do mundo e não uma simples refração ou reflexo[...]. Ele refrata o mundo na medida em que o reordena e reconstrói" (MARCUSCHI, 2008, p. 72). O autor complementa a sua explicação e afirma que os textos e/ou discursos se materializam através dos gêneros.
} 